\title{
An Analysis of Common Methods of Number Distinction in Tshivenda
}

\author{
Prof Nelson Mbulaheni Musehane \\ Language Research, Development and Consultancy Services, P.O.Box 358, Sibasa, 0970.Limpopo Province, \\ South Africa.
}

\begin{abstract}
Tshivenda is one of the eleven official languages in the Republic of South Africa. This language has structural features that are found in the methods of distinguishing pluralisation. This paper seeks to analyse the typological features of number of distinction and the process of the number distinction used among the Tshivenda culture. This will be accomplished by the processes of:

(a) Using plural affixes

(b) Using words of multitude

(c) Reduplication of nominal words

This will be accomplished by analysing oral speeches, published and unpublished literature using qualitative method because it is the appropriate method to get acceptable results.
\end{abstract}

Keywords: Analysis, common, methods. Number, distinction, Tshivenda

\section{Introduction}

All nouns in Tshivenda are classified into different classes or groups according to their meaning. One of the meanings is singularity and plurality. Musehane (1995:66) reaffirms that most nouns were divided into certain classes without showing any typical common characteristics. The common meaning is their singularity and plurality. In most cases the meaning of the nouns is a good indication of why it would have a specific prefix. The meaning of a noun is also more important than the class to which it belongs.

A prefix is defined by Poulos (1990:208) as the term used here in a general sense to refer to subject and object concords and also to the various tense formatives or markers. In fact, the term prefix in the context of the verb will refer to those entities that occur before the verb root, while the term suffix can be used to refer to those entities that occur after the verb root

\section{Theoretical Framework}

The researcher will analyse oral speeches of common words with the meaning of plurality in Tshivenda orally and in published and unpublished literature. This will be subjected to semantic theory i.e. theory of meaning.

\section{Plurality Expressed By Using Nominal Affixes}

Radford (1997) defines an affix as a grammatical morpheme which cannot stand on its own as an independent word, but which must be attached to an item of an appropriate kind. An affix which attaches to the beginning of a word (e.g.) un+ in unhappy is called a prefix; an affix which attaches to the end of a word (e.g. $+\mathrm{s}$ in chases is called a suffix).

In the following discussion, we will analyse prefixes that refer to pluralisation in Tshivenda.

\subsection{Plurality EXPRESSED BY USING NOMINAL PREFIXES}

There are 21 noun classes in Tshivenda numbered from 1 to 21.The class prefixes numbering with odd numbers are in singular whereas the even numbers show that the class prefixes are plurals. The following class prefixes have been dealt with.

1. Class $2 / 2 \mathrm{~b}$ are Plural noun classes

Class 2 Prefix: Vha->Vhathu 'Persons'

Vha> Vhashumi 'workers'

Class2b Vho> Vhomme 'mothers'

Vhomalume 'uncles'

For all nouns falling under these categories, the plurals class prefixes will be Vha- affixed to the noun stems -thu and-shumi respectively Vho- is affixed to noun stem -mme 'mother' and -malume' 'uncle' respectively. Such nouns will show the plurality of the singularity

For all nouns that fall under these categories will be in plural form 


\section{Class 4 Prefix: Mi- >Miri 'trees' \\ : Mi- $>$ Mishumo 'works'}

For all nouns falling under this category, the plural class prefix will be $M i$ - affixed to noun stems - $r i$ and-shumo respectively .Such nouns will show the plurality of the singularity.

3. Class 6 Prefix: $\quad M a->$ Matadulu 'heavens' Ma- >Mato 'eyes'

For all nouns falling under this category, the plural class prefix will be ma-affixed to noun stems -tadulu and-to respectively. Such nouns will show the plurality of the singularity.

4. Class 8 Prefix: Zwi- >Zwinoni 'birds'

$$
\text { : Zwi- >Zwilimo 'summers' }
$$

For all nouns falling under this category, the plural class prefix will be zwi-affixed to noun stems -noni andlimo respectively. Such nouns will show the plurality of the singularity.

5. Class 10 Prefix: $\quad$ Dzi- >Dzinngwa 'steeps or vertical rock faces'

: $\quad$ Dzi-- > Dzinyambo 'languages'

All nouns falling under this category, the singular class prefix will be $L u$ - affixed to noun stems $-w a$ and-ambo respectively. The plural class prefixes is $d z i$ - affixed to the noun stems -wa and-ambo respectively. Such nouns will show the plurality of the singularity.

These nouns are sometimes used without plural prefix $d z i$-To show that the noun is in the plural form and not in singular form; the noun will be identified by the subject concord in the plural .e.g.

6. Kholomo dzi a fula hatsi

Cattle are grazing

7. Class 14 Prefix: $H u$ - >Vhusunzi'any small ants'

: $\quad$ Vhu-- > Vhutanda 'long sticks'

For all nouns falling under this category, the plural class prefix will be Vhu- affixed to noun stems -sunzi andtanda respectively. Such nouns will show the plurality of the singularity.

8. Class $20 \quad \mathrm{Ku}-$ : is a singular class although it falls under even numbering.

Class Prefix Ku- >Kunoni 'small bird'

: Ku- >Kutanda 'small stick'

All nouns that fall under this category will be in singular form. The nouns in the plural form will sometimes fall under classes $Z w i$-and $V h u$ -

9. Class 8/14Prefixes: Zwi- >Zwinoni 'birds'

Vhu -> Vhutanda 'thin sticks'

10. Class 8/14 Prefixes: Zwi-- >Zwitanda 'long sticks'

: Vhu ->Vhutanda 'narrow sticks'

All nouns falling under this category, the singular class prefix is $K u$ - affixed to noun stems -noni and-tanda respectively .Such nouns will show the plurality of the singularity of prefixes $Z w i$ - and $V h u$-affixed to the noun stems -noni and -tanda respectively to express the plurality of the singularity .

\subsection{Plurality Expressed By Using Various Nominal Concords}

There are two nominal concords to be dealt with here and they are subject and object concords. The singular class prefixes have singular nominal concords whereas the plural nouns have concords which express plurality.

\subsubsection{Plurality Expressed By Using Subject And Object Concords}

$\begin{array}{llll}\text { Class } & \text { Prefix } & \text { Subject Concord } & \text { Object Concord }\end{array}$

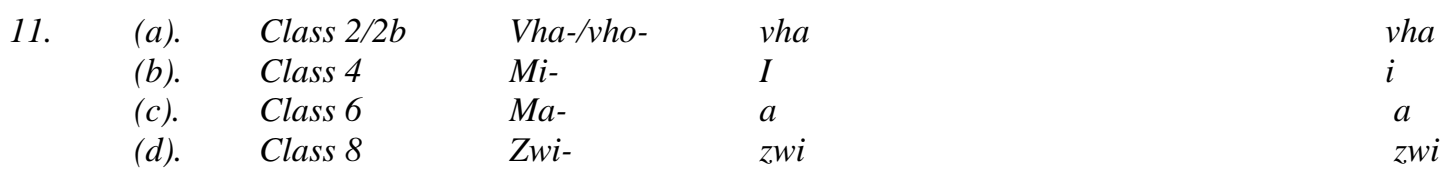


$\begin{array}{lllll}\text { (e). } & \text { Class } 10 & \text { Dzi- } & d z i & d z i \\ \text { (f). } & \text { Class } 14 & \text { Vhu- } & \text { vhu } & v h u\end{array}$

The above-mentioned classes have subject and object concords which are structurally the same as class prefixes, with the exception of classes 4 and 6, whose subject and object concords relinquish $m$ and the concord remains as a vowel only. This happens to subject and object concord with the bilabial sound $m$.

12. (a). Class.2:

$2 b$ :

(b). Class.4:

(c). Class. 6:

(d). Class. 8:

(e). Class. 10:

(f). Class. 14:
Vhathu vhal a vha2vhona (vhatukana)

People see them (boys)

Vhomalume vhal a vha2 vhona (vhatukana)

Uncles see them (boys)

Miri (m) ila (m) i2anwa (mitshelo)

Trees bear those (fruit)

Malwadze (m) al a (m) a2 tambudza (matshudeni)

Diseases harass them (students)

Zwinoni zwil a zwi2 fhata (zwitaha)

Birds build them (nests)

Kholomo dzil a dzi2mamisa (namana)

Cattle suckle them (calf)

Vhulimbo vhul a vhu2 fasha (vhutswiri)

Birdlime catches them (a vhutswiri bird)

In the preceding paragraph it was shown that vhal, $m$ (i) $1, m(a) 1$, zwil, dzil and vhul are subject concords which express the plurality. The wordsvha2, $m$ (i) 2,m(a)2, zwi2, dzi2 and vhu2 are object concords of the words in the same class and they are structurally the same as the subject concord as well as the class prefixes.

\subsubsection{Plurality Expressed Using Adjective Concords}

Plurality is expressed by words which are adjective concords found in the adjectives that qualify the nouns belonging to the following classes which are termed plurality classes. These are classes which express nouns in the plural form.

\section{Class Prefix Adjective Concord Adjectives}

\begin{tabular}{|c|c|c|c|c|}
\hline (a). & Class 2 & Vha- & vha- & vhahulu 'big ones' \\
\hline (b). & Class 4 & $M i-$ & $m i-$ & mihulu 'big ones' \\
\hline (c). & Class 6 & $M a-$ & $m a-$ & mahulu'big ones' \\
\hline (d). & Class 8 & $Z w i-$ & $z w i-$ & zwihulu'big ones' \\
\hline (e). & Class 10 & $D z i-$ & $d z i-$ & (dzi) khulu'big ones \\
\hline$(f)$. & Class 14 & Vhu- & vhu- & vhuhulu 'big ones' \\
\hline
\end{tabular}

The adjective concords of the above-mentioned classes are $v h a-, m i-, m a-, z w i-, d z i$-and $v h u$-. When the adjective concords are affixes to the adjective stems they form adjective vhahulu, mihulu, mahulu, zwihulu, khulu with the relinquishing of the adjective concord $d z i$-attached to the adjective stem -hulu respectively

\subsubsection{Plurality Expressed By Relative Concords}

Poulos (1990:141) says that there are three possible ways of forming direct relatives in Venda and they are:

\subsubsection{Plurality Expressed By Relative Concord + Verb Ending -ho}

A relative concord that is followed by a verb stem on to which a suffix -hois added. This suffix is known as a relative suffix

\section{Class Form}

14. Class $1 \mathrm{Mu}$

Class $1 \mathrm{Mu}$ -

Class 2/2b Vha- / Vho-

Class $4 \mathrm{Mi}$ -

\section{Relative Concord}

First person Plural

Person plural

$$
\begin{aligned}
& \text { ri 'we' } \\
& \text { ni 'you' } \\
& \text { vha 'they' } \\
& \text { I 'they' }
\end{aligned}
$$


Class $6 \mathrm{Ma}$ -

Class $8 \mathrm{Zwi-}$

Class 10 Dzi-

Class $14 \mathrm{Vhu}$ - a 'they'

zwi 'they'

$d z i$ 'they'

vhu- /hu- 'they'

15. (a). Rine ra vhona

Who are seeing?

(b). Inwi ni daho

You who are coming

(c). Vhathu vha daho

People who are coming

(d). Miri I waho

Trees that are falling

(e). Madi a rotholaho

Water that is cold

(f). Zwinoni zwi fhufhaho

....... Birds that are flying

(g). (Dzi) kholomo dzi fulaho

Cattle that are grazing

(h). Vhutanda vhu /hu vundeaho

Thin sticks those are broken

The words in bold are the relative concords in the preceding sentences. The preceding relative concords express the plurality of things referred to the antecedents which are the subjects of the sentences.

\subsubsection{Plurality Expressed By Verbal Relative Concord with -No- Followed A Verb}

\begin{tabular}{|c|c|c|}
\hline & Class & Form \\
\hline 16. & (a). & Class $1 \mathrm{Mu}$ - \\
\hline & (b). & Class $1 \mathrm{Mu}$ - \\
\hline & (c). & Class 2/2b Vha- / Vho- \\
\hline & (d). & Class $4 \mathrm{Mi}-$ \\
\hline & (e). & Class $6 \mathrm{Ma}$ - \\
\hline & $(f)$ & Class 8 Zwi- \\
\hline & (g). & Class $10 \mathrm{Dzi}$ - \\
\hline & (h). & Class 14 Vhu- \\
\hline
\end{tabular}

\author{
Relative Concord $+\mathbf{n o}+\mathbf{V}$-a \\ ri no da 'we who are coming' \\ ni no da 'you who are coming' \\ vha no da 'who are coming' \\ I no da 'that are coming' \\ a no da 'that are coming' \\ zwi no da 'that are coming' \\ dzi noda 'that are coming' \\ vhu/hu no da 'that are coming'
}

The plurality is expressed by the relative concords of the plural class prefixes. When these relative concords are employed, they express the plurality of nouns in class Mu- First person Plural and Second Person Plural. In addition to that, plurality is expressed by the relative concords of nouns in class Vha/Vho-, Mi-, Ma-, Zwi-, Dzi-, and Vhu- respectively.

\subsubsection{Plurality Expressed By Relative Pronoun Plus Relative Concord Followed By A Verb}

Here it is shown that a relative pronoun is followed by the relative concord and the verbs

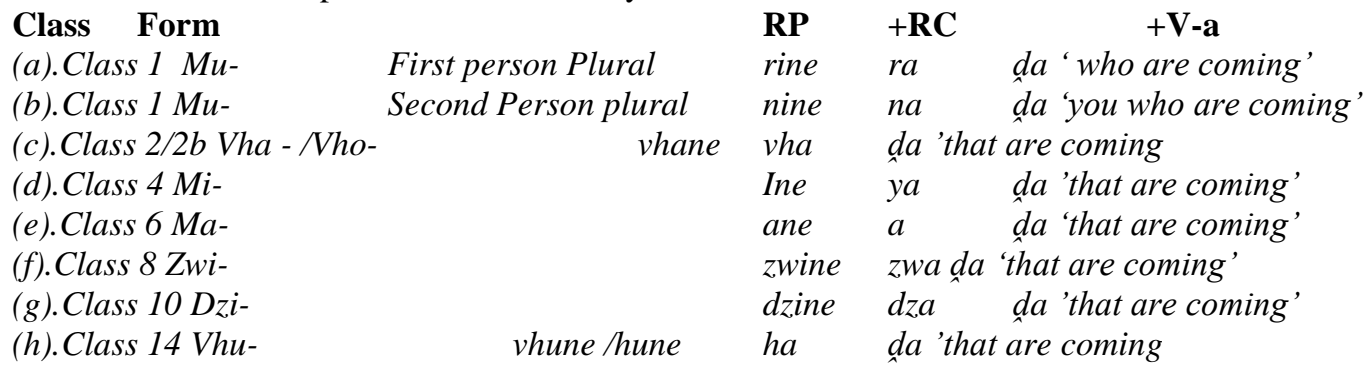

The plurality is expressed by the relative pronouns and the relative concords of the plural class prefixes, i.e. $\mathrm{Mu}$ First person Plural rine ra and Second Person Plural nine na. In addition to that, plurality of all other classes is expressed by relative concords of nouns in class Vha -/Vho- which is vhane vha, Mi- which is ine ya, Ma- 
which is ane a, Zwi- which is zwine zwa, Dzi- which is dzine dza, and Vhu- which is vhune ha/hune ha respectively.In that case the relative pronouns follow the relative concords whose plurality has been expressed.

\subsubsection{Plurality Expressed By Using Quantitative Concord}

The quantitative concords of plural class prefixes has a tendency of expressing plurality

\section{Class Form}

18. (a) Class $1 \mathrm{Mu}$ -

(b) Class $1 \mathrm{Mu}$ -

(c) Class 2/2b Vha -/Vho-

(d) Class $4 \mathrm{Mi}$ -

(e) Class $6 \mathrm{Ma}$ -

(f) Class 8 Zwi-

(g) Class 10 Dzi-

(h) Class 14 Vhu-

\section{Relative Concord}

First person Plural

Person plural

$$
\begin{aligned}
& \text { ro- 'we' } \\
& \text { no- 'you' } \\
& \text { vho-'they' } \\
& \text { yo- 'they' } \\
& \text { o- 'they' } \\
& \text { zwo- 'they' } \\
& \text { dzo- 'they' } \\
& \text { ho- 'they' }
\end{aligned}
$$

19. (a). Rine rothe 'we all'

(b). Inwi nothe'you all'

(c). Vhathu vhothe'all people'

(d). Miri yothe 'all trees'

(e). Madi othe'all water'

(f). Zwinonizwothe'all birds'

(g). (Dzi) kholomodzothe' all cattle'

(h). Vhutanda hothe'all thin sticks'

The above words in bold are the quantitative concords in the above mentioned sentences. The above quantitative are formed by the quantitative concords affixed to the quantitative stems - the. These quantitatives express the plurality of things referred by the antecedent which are the subjects of the sentences.

\subsubsection{Plurality Expressed By Using Absolute Pronoun Concords} the plurality.

It is found that the absolute pronoun concords for plural class prefixes have the potential of expressing

Class

20. (a) Class 2

(b) Class 4

(c) Class 6

(d) Class 8

(e) Class 10 Dzi-

(f) Class14

Prefix

Vha-/Vho-

$M i-$

$M a-$

Zwi-

Vhu-

\section{Absolute Pronoun Concord}

vha-

mi-

ma-

$z w i-$ $d z i$

vhu-
Absolute

vhone < vhaone 'they'

yone<ione 'they'

one <aone'they'

zwone <zwione 'they'

dzone < dzione 'they'

hone<huone 'they'

The preceding section consists of the absolute pronoun concords in bold letters. To the absolute pronoun concordswe affix the root-0- and suffix -ne to form an absolute pronouns vhone <vhaone,yone <ione, one <aone,zwone<zwione, dzone<dzione and hone<huone respectiverly.The absolute pronoun concords are structurally the same as the class prefixes and the absolute pronoun concords express the plurality of the nouns referred to by the absolute pronoun concords.

\subsubsection{Plurality Expressed By Using Demonstrative Pronoun Concords}

$\begin{array}{llllll}\text { Class Prefix } & \text { D.P. Concord } & \text { D1 } & \text { D2 } & \text { D3 } & \text { D4 }\end{array}$

21. (a) Class 2 Vha -/Vho- vha-

(b) Class $4 \mathrm{Mi}$ -

(c) Class $6 \mathrm{Ma}$ -

(d) Class 8 Zwi-

(m) $i$ -

(m) $a-$

(e) Class $10 \mathrm{Dzi}$ -

$z w i-$

$d z i-$

vhu- huno uhu uho

vhano avha avho

ino iyi iyo

ano aya ayo

zwino izwi izwo

dzino idzi idzo

D4

vhala

ila

ala

zwila

dzila

vhuno uvhu uvho

these here, there hula

vhula

over there 
The above class prefixes have the same demonstrative PronounConcords which are structurally similar to the class prefixes with the exception of class 4 and 6prefixes with bilabial sounds. These Demonstrative Pronoun concords have a tendency of relinquishing $m$ and remain $i$ in class 4 and remains without an $m$ in class 6 respectively. These demonstrative Pronoun Concords have a potential of expressing the plurality of singularity of nouns in the other classes.

\subsubsection{Plurality Expressed By Using the Possessive Concords}

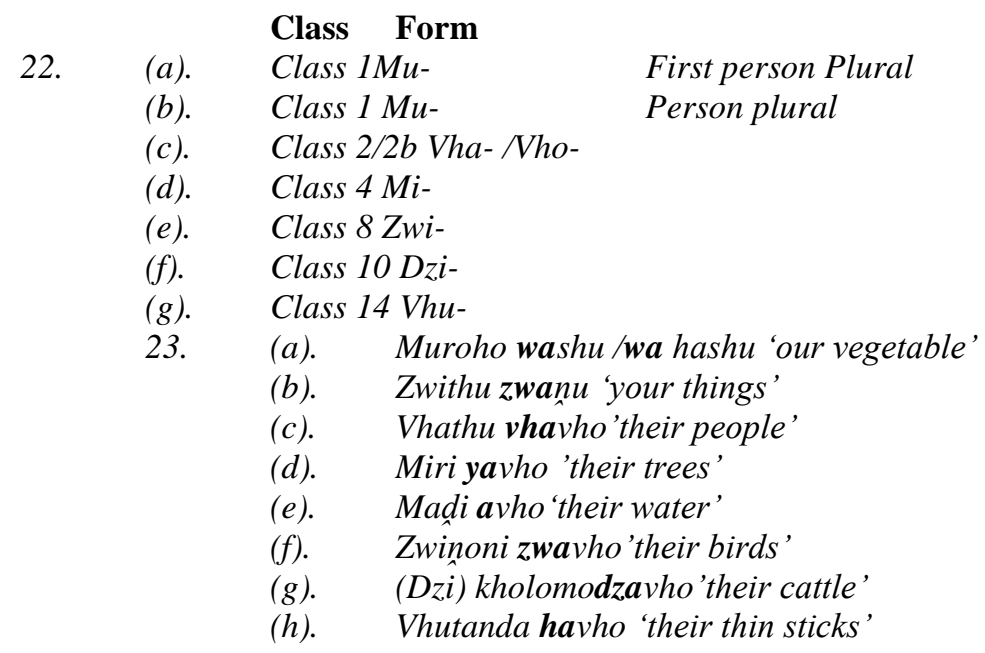

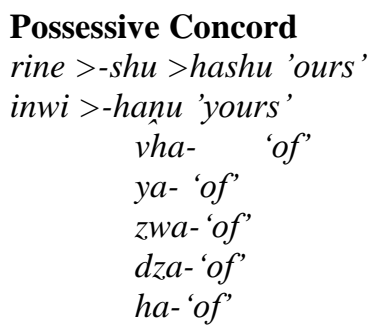

The preceding mentioned words in bold type are possessive concords in the preceding mentioned sentences. The possessives have been formed by the possessive concords (formed from the subject concord plus stem $a>u a>w a$ ) affixed to the possessive stems. The possessive stems could be an absolute pronouns, nouns and other substantives, In the above case the possessive stems are - shu,-nu,-vho which is the short form of the absolute pronoun vhone>-vho. This possessive concord has the potential of expressing the plurality of things referred by the antecedent which are the subjects of the sentences.

\subsubsection{Plurality Expressed By Using Auxiliary Verbs}

Some of the auxiliary verbs have the potential of expressing the plurality. In other words when such auxiliary verbs are in a sentence they have the tendency of expressing plurality referring to many times.

24. (a). Tolou: Ndi tolou mu vhona 'I always see him/her'
(b). Twwa: Nditwa ndi tshi mu vhona 'I occasionally see him',
(c). Dzulela: Ndidzulela u mu vhona 'I occasionally see him/her'

When the above statements are uttered one has the sense that it refers to plurality of seeing him on several occasions but not once.

\subsubsection{Plurality Expressed By Using Suffixes In Imperative Mood sentence}

The imperative sentences are the sentences in the imperative mood. These are sentences in which commands or instructions are given. Sometimes instructions are given to many persons instead of one person.

(a).Vhala! Read! > An instruction is given to one person

(b).Vhalai! Do read! > $\quad$ An instruction or command is given to one persons

reflected by -i from iwe 'you'which is an absolute pronoun for the first person, singular

PouIos (1990:233)is in agreement that the verb root is $-v h a l-$ and the suffix is $-a$.The $-n i$ form is merely a plural marker .Note also that there is no subject concord in those sentences. The $-n i$ is derived from absolute pronoun of second person plural.

25. Vhalani!'you read'

\section{Plurality Expressed By Using Words Of Multitudes}

26. (a). Murivha $>$ Ndi vhona murivha wa zwinoni

I am seeing a swarm of birds

(b). Guma $>$ Ndi khou vhona guma la notshi

I am seeing a swarm of bees

(c). Murutshe>Murutshe wa nzie 


\section{A stalk of grasshopper}

(e). Lutsinga $>$ Lutsinga lwa notshi

\section{A flight of bees}

In the preceding section, the words in bold letters mean many things in a group. The word murivha refers to a group of birds flying together. The second one guma refers to a swarm of bees. The third one refers murutshe which is a stalk of grass or thin wand used to skewer crickets, grasshoppers and figs .The word shovu is a plantation of many banana trees whereas lutsinga refers to a bowstring; line as of flight of bees or grasshoppers or villages strung out. When these words are uttered one should know that it does not refer to one thing. It refers words showing a multitude in which plurality is expressed in a way.

\section{Plurality Expressed By Using Reduplication Of Nominal Words}

Tshivenda like any other language of the world has the properties of expressing plurality when using reduplicated nominal words. Crystal (1991:293) defines reduplication (reduplicate-e,-vie) as

A term in Morphology for a process of repetition whereby the forms of a prefix/suffix reflects certain phonological characteristics of the root. This process may be found in Greek, where the initial consonant of the root is reduplicated in certain grammatical contexts (perfective).In Tshivenda the following are good examples of reduplication of the nominal words.

27. (a). Ndi mu vhona duvha na duvha

I always see him/her

(b). $\quad$ Ndo tshimbila mudi nga mudi ndi si mu wane

I went to all homesteads but could not find him

(c). Ro yam muvhundu nga muvhundu

I went to every village

(d). Ro dzhena nndu nga nndu ra si wane tshithu

We entered every house but have found anything

In the above sentences words have been reduplicated such as duvha na duvha, mudi na mudi, muvhundu na muvhundu and nndu nga nndu has the potential of expressing plurality. In the above sentences what is expressed by the verb occurs several times.

Tshivenda like other languages has the capacity of expressing the plurality when using reduplication of nominal words. Basumatary (2013:194) affirms that in these sense plurality is expressed by reduplication of words of noun class .Sometimes a word is uttered repetitively and used in representation of plurality.

\section{Conclusion}

The above-mentioned discussion has analysed the way in which plurality is expressed in Tshivenda. The following ways have been established. The use of class prefixes, uses of subject and object concords have been employed. The adjective, relative, quantitative, absolute, demonstrative pronoun concords have been employed to express the plurality. Besides that, the uses of imperative suffixes, auxiliary verbs and multitude words have been employed to express the plurality of nouns in Tshivenda. The discussion has succeeded in showing /illustrating words used to express the plurality of various nouns in Tshivenda.

\section{Acknowledgment}

The researcher wishes to acknowledge all members of the M.E.R Mathivha Centre for African Languages, Arts and Culture who consciously or unconsciously assisted me to be engaged in all research activities that took place while I was still attached to the University of Venda before retirement.

\section{References}

[1] Basumatary, P.C 2012:Common Methods of Number Distinction in Boro and Other Cognate Languages of North-East India. In USChina Foreign Language Vol 11, No.3 of 2013 P 191-195

[2] Milubi, N.A: Ngoma ya Vhatei Gireidi 10-12, Polokwane, NAM Publishers

[3] Milubi, N.A and Madadzhe, R.N1990: Mutoli wa Tshivenda Murole wa 8, Sovenga, NAM Publishers

[4] Musehane, N.M 1995: The Nominal Compound in Tshivenda, Unpublished Doctoral Thesis, Stellenbosch, University of Stellenbosch

[5] Napoli, D.J 1996: Linguistics-An Introduction, New York, Oxford University Press

[6] Poulos, G 1990 A Linguistic Analysis of Venda, Pretoria, Via Afrika Ltd

[7] Radford, A 1997: Syntax-A minimalist introduction, Cambridge University Press. Great Britain

[8] Spencer, A 1991: Morphological Theory -An Introduction to Word Structure in Generative Grammar, Blackwell Publishers, Cambridge

[9] Van Warmelo, N.J 1989 :Venda Dictionary, Pretoria J.L.Van Schaik Publishers 